\title{
openheart Five-year outcomes following left ventricular assist device implantation in England
}

\author{
Alex Bottle (D) , ${ }^{1}$ Puji Faitna, ${ }^{1}$ Paul P Aylin (D) , ${ }^{2}$ Martin R Cowie (D) ${ }^{3}$
}

\begin{abstract}
- Additional supplemental material is published online only. To view, please visit the journal online (http://dx.doi.org/10.
\end{abstract} 1136/openhrt-2021-001658).

To cite: Bottle A, Faitna P, Aylin PP, et al. Five-year outcomes following left ventricular assist device implantation in England. Open Heart 2021;8:e001658. doi:10.1136/ openhrt-2021-001658

Received 19 March 2021 Revised 19 April 2021 Accepted 22 April 2021

D Check for updates

(c) Author(s) (or their employer(s)) 2021. Re-use permitted under CC BY. Published by BMJ.

${ }^{1}$ School of Public Health, Faculty of Medicine, Imperial College London, London, UK

${ }^{2}$ General Practice and Public Health, Imperial College London, London, UK

${ }^{3} \mathrm{~S} c h o o l$ of Cardiovascular Medicine \& Sciences, Faculty of Life Sciences \& Medicine, King's College London, London, UK

Correspondence to Professor Martin R Cowie, School of Cardiovascular Medicine \& Sciences, Faculty of Life Sciences \& Medicine, King's College London, London, United Kingdom; martin.cowie@ kcl.ac.uk

\section{ABSTRACT}

Objective Implant rates of mechanical circulatory supports such as left ventricular assist devices (LVAD) have steadily increased in the last decade. We assessed the utility of administrative data to provide information on hospital use and outcomes.

Methods Using 2 years of national hospital administrative data for England linked to the death register, we identified all patients with an LVAD and extracted hospital activity for 5 years before and after the LVAD implantation date. Results In the two index years April 2011 to March 2013, 157 patients had an LVAD implanted. The mean age was 50.9 (SD 15.4), and $78.3 \%$ were men. After 5 years, $92(58.6 \%)$ had died; the recorded cause of death was noncardiovascular in $67.4 \% .42(26.8 \%)$ patients received a heart \pm lung transplantation. Compared with the 12 months before implantation, the 12 months after but not including the month of implantation saw falls in total inpatient and day case admissions, a fall in admissions for heart failure (HF), a rise in non-HF admissions, a fall in emergency department visits not ending in admission and a rise in outpatient appointments (all per patient at risk). Postimplantation complications were common in the subsequent 5 years: $26.1 \%$ had a stroke, $23.6 \%$ had a device infection and $13.4 \%$ had a new LVAD implanted. Conclusions Despite patients' young age, their mortality is high and their hospital use and complications are common in the 5 years following LVAD implantation. Administrative data provide important information on resource use in this patient group.

\section{INTRODUCTION}

Heart failure (HF) affects 26 million people worldwide, and its incidence is growing in the UK. ${ }^{1-3} \mathrm{HF}$ is expensive to treat and places a significant burden on healthcare systems. ${ }^{34}$ Improvements in HF treatments have meant that a growing number of patients live to develop severe HF, and, for these patients, heart transplants remain the gold standard treatment. ${ }^{56}$ Unfortunately, there is a worldwide shortage of heart donors, highlighting the practical limitations of heart transplants. ${ }^{67}$ Consequently, there has been a rise in mechanical circulatory support (MCS) implants to help bridge this gap. ${ }^{89}$

\section{Key questions}

What is already known about this subject?

- Implant rates of mechanical circulatory supports such as left ventricular assist devices (LVAD) have steadily increased in the last decade. Most studies do not report outcomes beyond 2 years, and much information comes from trials, which may not be generalisable.

What does this study add?

- Despite patients' young age, their mortality is high and their hospital use and complications are common in the 5 years following LVAD implantation. Administrative data provide important information on resource use in this patient group that can be more timely than that from registries.

How might this impact on clinical practice?

- National data sets can help inform assessment of outcome and healthcare utilisation for advanced heart failure therapies such as LVAD.

MCS is a good option for refractory patients with $\mathrm{HF}$ who are ineligible for heart transplants. ${ }^{10} 11$ Implant rates of MCS such as left ventricular assist devices (LVAD) have steadily increased in the last decade, offering improvements to the survival and quality of life of patients. ${ }^{5} 91213$

Many studies assessing LVAD outcomes use randomised control trials (RCT), which may not be generalisable due to restrictive RCT selection criteria. ${ }^{14}$ Survival estimates following an LVAD implant range from $56 \%$ to $87 \%$ at 1 year and $43 \%$ to $84 \%$ at 2 years; most do not report survival rates beyond 2 years. ${ }^{7910}$ More LVAD studies are needed to assess longer term survival, costs and complications, as this has limited cost-effectiveness evaluations. ${ }^{15}$ Administrative data can offer insights on longer term outcomes from a broader population as it has national coverage. ${ }^{14}$ The National Institute for Health and Care Excellence recommends using existing real-world data to inform decisionmaking. ${ }^{16}$ This study is the first to use English 
hospital administrative data, Hospital Episode Statistics (HES), to explore the longer term survival rates, complications and hospital service use following LVAD implantation.

\section{MATERIALS AND METHODS \\ Data}

We extracted records from England's national hospital administrative database, HES, which comprises over 125 million admitted patient, outpatient and emergency department (ED) records from the National Health Service (NHS) annually. Submission is mandatory. Inpatient and day case diagnostic coding uses ICD-10 (International Statistical Classification of Diseases and Related Health Problems 10th Revision), but ED records use a much broader and more symptom-based approach. Each admission is assigned a primary ICD-10 diagnostic code by trained staff who determine this to be the primary reason why the patient is being treated; 19 secondary ICD-10 codes relate to comorbidities or complications during the admission. Up to 24 procedures are coded using the UK's Office of Population Censuses and Surveys (OPCS) system. With a time-lag, the national HES database is linked to the national deaths registry, maintained by the Office of National Statistics, thereby capturing the date and causes of all deaths, including out-of-hospital deaths. We used HES data from April 2006 to March 2018, with linked death data to July 2018; for ED records reliable data only existed from April 2009.

\section{Cohort and outcomes}

Using 2 years of HES, April 2011 to March 2013, we defined a cohort based on the inpatient admission record covering the implantation of each patient's first device during the 2 years: the procedure date for this was their 'index date'. An OPCS procedure code of K54.1 ('open implantation of ventricular assist device') in any position was used for the LVAD implantation. Patients with records with codes for the implantation or removal of such devices in the previous 5 years were excluded (K54.2 is the code for removal). Comorbidities were derived from the index admission and any admission in the previous year.

Total mortality, hospital activity by sector-outpatient clinic, ED, day case and inpatient admission-were the main outcomes. We divided inpatient and day case activity into that for HF (ICD-10 I50) and that for any non-HF conditions using the primary diagnosis field. We identified postimplantation admissions for removal of the device, implantation of a new LVAD, haemorrhagic stroke and ischaemic stroke (and all types combined). ICD-10 codes for the complications are given in the online supplemental appendix. Heart or heart and lung transplantation procedures were identified using OPCS codes K01 and K02. For all these outcomes, all consultant episodes within the admission and all diagnosis and procedure fields were examined.

\section{Analysis}

A Kaplan-Meier plot described the 5-year mortality and median survival since the index date. For hospital activity and reference costs, we calculated the monthly rates per patient at risk, that is, per patient still alive, for five years before and after the index month, giving 121 months (periods of 30 days) in total. Using the AalenJohansen method to handle competing risks, we plotted the proportions of patients over time on support, with a transplant or explanted (with the device removed). SAS V.9.4 was used for all analyses.

\section{Ethics}

We have the approval from the Secretary of State and the Health Research Authority under Regulation 5 of the Health Service (Control of Patient Information) Regulations 2002 to hold confidential data and analyse them for research purposes (CAG ref 15/CAG/0005). We have approval to use them for research and measuring quality of delivery of healthcare, from the London-South East Ethics Committee (REC ref 15/LO/0824). We attest our strict compliance with the ISHLT ethics statement.

\section{Patient and public involvement}

Patients or the public were not involved in the design, or conduct, or reporting or dissemination plans of our research.

\section{RESULTS}

\section{Patient characteristics}

For the two index years from April 2011 to March 2013, there were 157 patients with an LVAD implanted. No patients were excluded due to missing or invalid data. The mean age was 50.9, and more than three-quarters were men. Patients had a median of three comorbidities listed in table 1 (IQR 2-5).

\section{Overall survival and time to other outcomes}

By 5 years after the index date, 92 patients had died, for an all-cause case fatality rate of $58.6 \%$; the 1 -year rate was $39.5 \%$, the 2-year rate was $47.8 \%$. Figure 1 shows the Kaplan-Meier plot. Median survival was 960 days (2.6 years). HF was given as the main cause for $12.4 \%$ of deaths; other cardiovascular but non-HF causes accounted for $20.2 \%$, with the remaining $67.4 \%$ noncardiovascular and non-HF.

During the 5 years' follow-up, heart \pm lung transplantation was performed in 42 patients $(26.8 \%)$ including during the index admission, with 14 deaths; excluding the index admission, there were 30 transplants with seven deaths. The median acute hospital length of stay (LOS) for the index stay was 24 nights (IQR 9-49); including any interhospital transfers gave a median LOS of 40 nights (IQR 23-70).

The median time to renewal in the 21 patients who had a second LVAD was 135 days (IQR 8-463).

The median time on support was 351 days (IQR 13-1171), estimated using the Kaplan-Meier method 


\begin{tabular}{lc}
\hline $\begin{array}{l}\text { Table } 1 \text { Patient characteristics on admission for the LVAD } \\
\text { implantation }\end{array}$ \\
\hline Factor & N (\% of total) \\
\hline All patients & 157 \\
\hline Age 18-39 & $34(21.7)$ \\
\hline Age 40-64 & $92(58.6)$ \\
\hline Age 65-74 & $22(14.0)$ \\
\hline Age 75-84 & $8(5.1)$ \\
\hline Age 85+ & $1(0.6)$ \\
\hline Age: mean (SD) & $50.9(15.4)$ \\
\hline Women & $34(21.7)$ \\
\hline Men & $123(78.3)$ \\
Coronary artery bypass graft & $29(18.5)$ \\
\hline Percutaneous coronary intervention & $19(12.1)$ \\
\hline Diabetes & $24(15.3)$ \\
\hline Stroke & $14(8.9)$ \\
\hline Pneumonia & $22(14.0)$ \\
\hline Ischaemic heart disease & $92(58.6)$ \\
\hline Atrial fibrillation & $74(47.1)$ \\
\hline Valvular disorders & $99(63.1)$ \\
\hline Hypertension & $61(38.9)$ \\
\hline Peripheral vascular disease & $37(23.6)$ \\
\hline Chronic pulmonary disease & $29(18.5)$ \\
\hline Renal disease & $45(28.7)$ \\
\hline Obesity & $16(10.2)$ \\
\hline Dementia & $0(0)$ \\
\hline Other mental health condition & $7(17.2)$ \\
\hline
\end{tabular}

LVAD, left ventricular assist device.

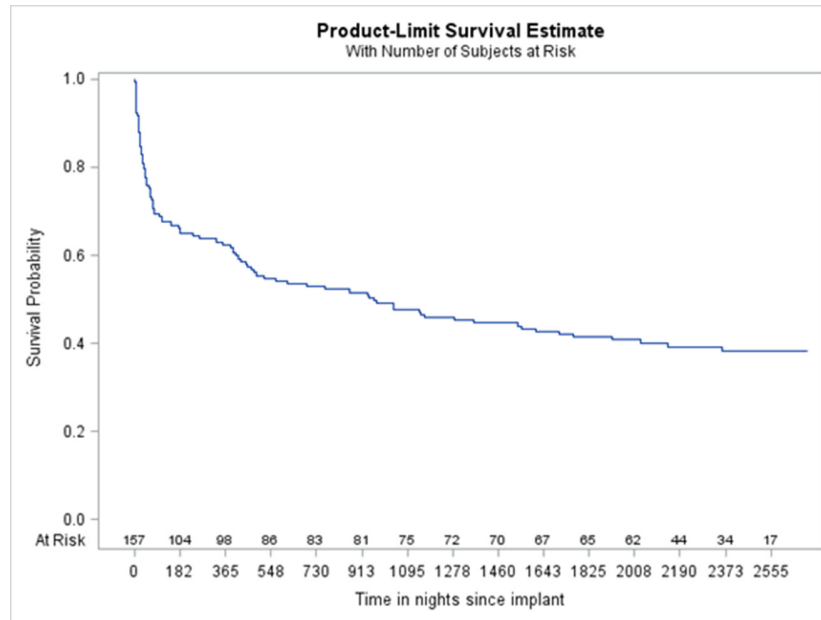

Figure 1 Kaplan-Meier plot of 5-year mortality following LVADs implanted between 1 April 2011 and 31 March 2013, plotted as days since implantation date. LVAD, left ventricular assist device.

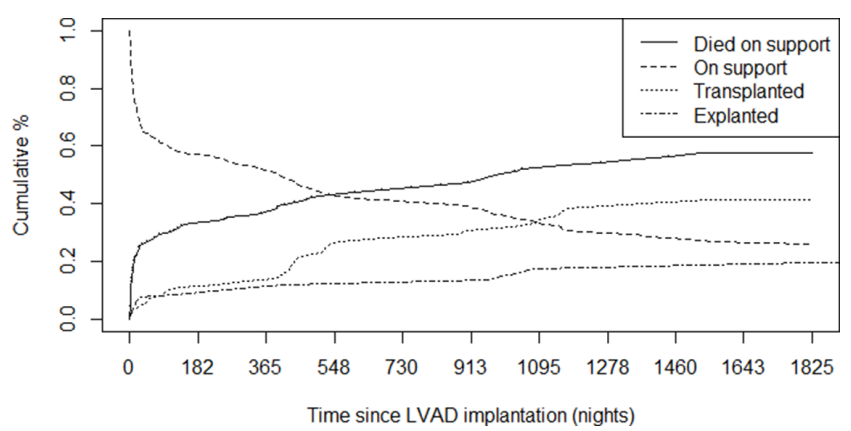

Figure 2 Cumulative incidence over 5 years of transplants, death and explants following LVADs implanted between 1 April 2011 and 31 March 2013. LVAD, left ventricular assist device.

and defining transplant, explant or death as the end of support.

The median time to transplant in the 42 patients who had one was 433 days (IQR 82-900).

Figure 2 shows the cumulative incidence of transplant, death and explant for all 157 patients.

\section{Hospital activity in the 5 years before and 5 years after implantation}

Figure 3 shows hospital admissions, expressed as admissions per patient at risk. The unplanned admissions with LOS $>0$ days (ie, at least one night) dominated for the index admission and were the most common type of admission both before and after the index date. In figure 4, all admissions (elective inpatient admissions, day cases and emergency inpatient admissions) have been split by the coded primary diagnosis into two groups: HF and non-HF admissions. HF admissions fell and non-HF admissions rose after implantation (table 2).

\section{Activity and costs in the year before and after the index month}

The peak in ED visits not ending in admission occurred in the month before the index month. Mean outpatient

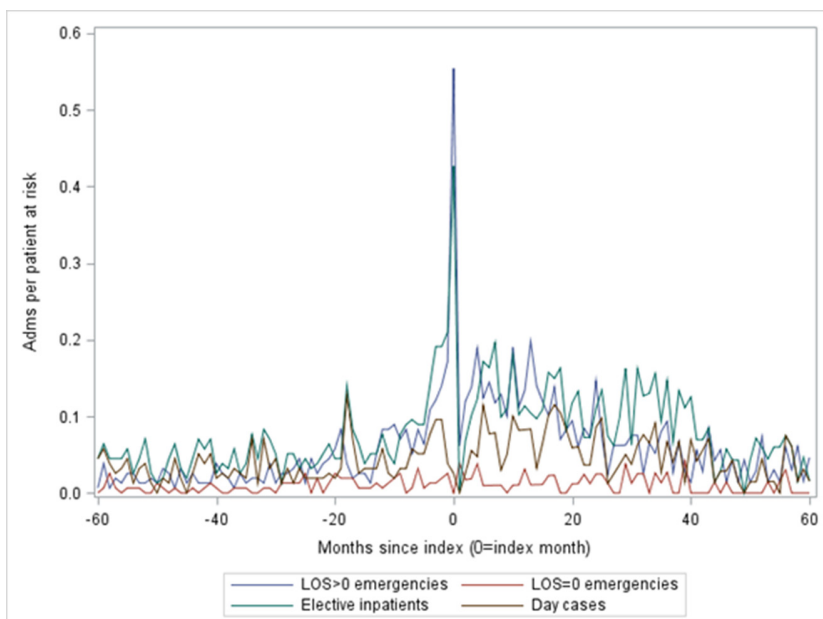

Figure 3 Admissions before and after LVAD implantation by type. LVAD, left ventricular assist device. 


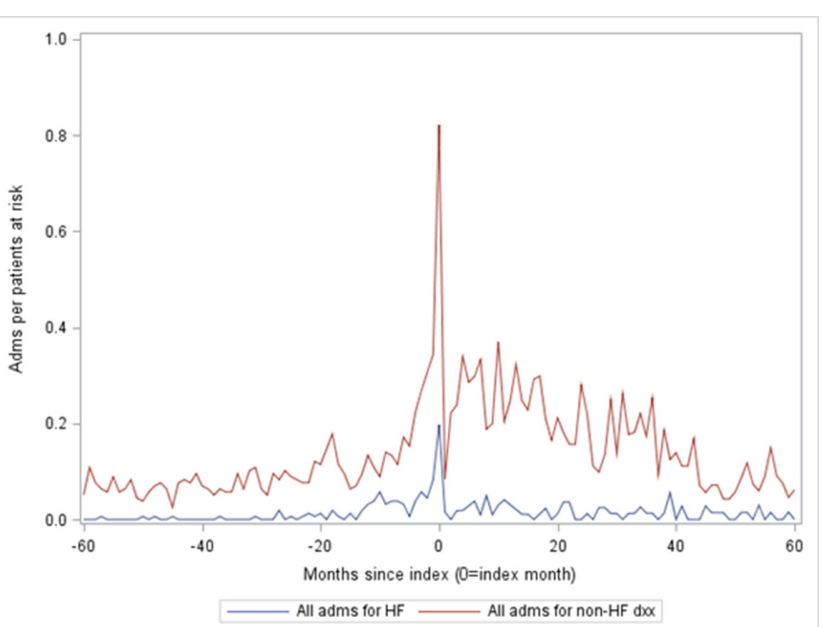

Figure 4 All admissions per person at risk, split by the primary diagnosis into HF (lower line) vs non-HF (upper line). HF, heart failure.

appointments per patient at risk rose after the index month (table 3 ).

\section{Admissions for device complications}

Table 4 shows the number of patients with postimplantation stroke and specific device-related coded complications. Due to the lack of present on admission information in HES, figures are presented in two ways, with and without including the index admission. Online supplemental figure A2-A4 shows the time to stroke, which for the majority was within 500 days of implantation.

\section{DISCUSSION}

\section{Summary of findings}

Despite being young compared with patients in some previous studies, our set of unselected patients with LVAD were multimorbid, with high postimplantation morbidity, mortality and use of hospital services. Within 5 years of LVAD implantation, nearly $60 \%$ of our study population had died, the majority from noncardiovascular causes, and approximately one in four had a heart transplant. The median time on support was just short of a year, with huge variation. Thirteen per cent of patients

Table 2 Total inpatient and day case admissions by primary diagnosis in the 12 months before and the 12 months after the index month (index month not included)

\begin{tabular}{lll}
\hline & $\begin{array}{l}\mathbf{1 2} \mathbf{~ m} \text { before } \\
\text { index }\end{array}$ & $\begin{array}{l}\mathbf{1 2} \mathbf{~ m} \text { after } \\
\text { index }\end{array}$ \\
\hline All admissions & 421 & 344 \\
Admissions per patient at risk & 0.223 & 0.271 \\
HF admissions & 78 & 30 \\
Admissions per patient at risk & 0.0414 & 0.0236 \\
Non-HF admissions & 343 & 314 \\
Admissions per patient at risk & 0.1821 & 0.2475 \\
\hline
\end{tabular}

HF, heart failure. had a second LVAD implanted within 5 years of their first. Hospital admissions per person at risk rose to a peak at the month of implantation before falling away and were dominated by unplanned stays of at least one night with a non-HF primary diagnosis, in common with hospitalised patients with HF in general. ${ }^{17}$ After implantation, ED visits fell but outpatient appointments rose. Stroke and infections from the device were common, with around one in four patients affected by each.

\section{Comparison with previous studies}

Comparisons with other studies are complicated by the different types of device, patient selections, treatment goals and follow-up durations. Our study had the longest follow-up. Two years after implantation, our mortality rate of $48 \%$ is higher than that of MOMENTUM-3 (Multicenter Study of MagLev Technology in Patients Undergoing Mechanical Circulatory Therapy with HeartMate 3 ) (25\% and $32 \%$ for the two trial groups), ${ }^{18}$ the HeartMate II mid-trial (39\% and $35 \%)^{11}$ and Tsiouris et al's single-institution cohort (29\%, although their 4-year rate was $55 \%$, which was slightly higher than ours),${ }^{19}$ but it is lower than in an older study from $2007(69 \%)^{20}$; our 1-year rate of $40 \%$ is higher than that from the European INTERACS trial-based registry, which reported rates of $24 \%$ during the trial and $15 \%$ post-trial. ${ }^{21}$ A recent report from the ELEVATE Registry (Evaluating the HeartMate 3 with Full MagLev Technology in a Post-Market Approval Setting), designed to study long-term outcomes with the more modern Heartmate 3 devices, gave a 2-year death rate of just $17 \% .^{22}$ There is a trend towards lessinvasive nonsternotomy approaches. For example, the LATERAL single-arm trial evaluated the HeartWare centrifugal-flow ventricular assist device system reported that $88 \%$ of its 144 patients were alive and free from disabling stroke, transplantation and explantation at 6 months. ${ }^{23}$

Complications of LVAD therapy include bleeding, infection, pump thrombosis, right HF, device malfunction and stroke. ${ }^{24}$ Bleeding is the most common but is not well captured by ICD-10. We report 5-year rates of devicerelated infection of $23.6 \%$ and any stroke of $26.1 \%$. A

Table 3 Total ED visits not ending in admission and total outpatient department appointments for each group in the 12 months before and the 12 months after the index month (index month not included)

\begin{tabular}{lll}
\hline Activity & $\begin{array}{l}\mathbf{1 2} \mathbf{~ m} \text { before } \\
\text { index }\end{array}$ & $\begin{array}{l}\mathbf{1 2} \mathbf{~ m} \text { after } \\
\text { index }\end{array}$ \\
\hline $\begin{array}{l}\text { Total ED visits not ending in } \\
\text { admission }\end{array}$ & 80 & 53 \\
Visits per patient at risk & 0.059 & 0.051 \\
\hline Total cost (£) & 142702 & 222405 \\
Appointments per patient at risk & 0.75 & 1.64 \\
\hline
\end{tabular}

ED, emergency department. 
Table 4 Five-year complications following LVAD implantation

\begin{tabular}{|c|c|c|c|c|}
\hline \multirow[b]{2}{*}{ Complication } & \multicolumn{2}{|l|}{ Not including index admission } & \multicolumn{2}{|c|}{ Including index admission } \\
\hline & $\begin{array}{l}\text { Number (number of deaths } \\
\text { if stroke) }\end{array}$ & Rate as \% & $\begin{array}{l}\text { Number (number of } \\
\text { deaths if stroke) }\end{array}$ & Rate as \% \\
\hline Haemorrhagic stroke & $5(3)$ & 3.2 & $11(8)$ & 7.0 \\
\hline Cerebral infarction & $13(5)$ & 8.3 & $22(11)$ & 14.0 \\
\hline Haemorrhagic stroke or cerebral infarction* & $17(8)$ & 10.8 & $32(19)$ & 20.4 \\
\hline Any stroke (ICD-10 I60-I64) & $24(14)$ & 15.3 & $41(27)$ & 26.1 \\
\hline Infection from device & 33 & 21.0 & 37 & 23.6 \\
\hline New LVAD implanted & 21 & 13.4 & 21 & 13.4 \\
\hline
\end{tabular}

*One additional patient had an admission with ICD-10 I64X (stroke not specified as haemorrhage or infarction).

LVAD, left ventricular assist device.

2009 trial $^{11}$ comparing continuous flow with pulsatile flow LVADs found the former to have lower adverse event rates, including LVAD-related infection of 0.48 per patient-year (therefore, $48 \%$, around two times our rate despite only having a 2-year follow-up) and a stroke rate of 0.13 per patient-year (therefore, $13 \%$, lower than our rate at 2 years). A 2011 one-institution series found a drive-line or pocket infection rate of 0.72 per patientyear in their 86 patients with continuous flow devices. ${ }^{25}$ The MOMENTUM-3 trial's 2-year stroke rates were 10\% for the HeartMate $3 \%$ and $19 \%$ for the HeartMate II devices. $^{18}$

\section{Strengths and limitations}

Our study benefits from a 5-year follow-up period with national data and capture of all deaths occurring in England by linkage to the Office of National Statistics death register. A British Heart Foundation report ${ }^{26}$ and NHS Blood and Transplant report ${ }^{27}$ analysed LVADs or ECMOs during the 11-year period from April 2007 to March 2017; for the last 3 years, there were 82 long-term LVADs per year. We had 157 in 2 years, which matches the external source well. The type of LVAD is not recorded in HES. An inevitable downside of our longer follow-up is that we are evaluating older technologies.

We grouped the cause of death broadly to reduce misclassification, which can be a problem with death certificates. The primary diagnosis and procedure fields are known to be highly accurate, ${ }^{28}$ giving confidence in the numbers of LVADs (as noted above) and heart transplants. Secondary diagnosis coding is less accurate and subjected to variations by hospital. ICD-10 coding limitations restricted what we were able to report regarding disease severity and complications. Bleeding is poorly captured and, in our experience, blood transfusion during or after surgery often unrecorded. For infections, we used the device-specific ICD-10 $\mathrm{T}$ code rather than a broader set of infection codes, which would have captured more but at the cost of being less likely to relate specifically to the device. For stroke, we used several definitions. As HES lacks present on admission information, we ran the complication analysis with and without the index admission. As with infections, stroke codes in the index admission could sometimes relate to previous events rather than to the LVAD.

\section{CONCLUSIONS}

Mortality is high and hospital use and complications are common in the 5 years following LVAD implantation. Administrative data provide important information on resource use in this patient group. Such data have national coverage and, whereas registries typically publish annual reports, ${ }^{29} 30$ HES is available to researchers only 3 months behind real time and can, therefore, give more timely estimates of hospital use.

Contributors $A B$ and $M R C$ conceived the study and obtained funding. $A B$ analysed the data. $A B$ and PF drafted the manuscript. All authors edited the manuscript for content.

Funding This work was supported in part by a Medtronic grant to AB and MRC and by a grant to the Dr Foster Unit (see competing interests).

Competing interests This work was supported in part by a Medtronic grant to $A B$ and MRC. The Dr Foster Unit is an academic unit in the Department of Primary Care and Public Health, within the School of Public Health, Imperial College London. The unit receives research funding from Dr Foster Intelligence, an independent health service research organisation (a wholly owned subsidiary of Telstra). The Dr Foster Unit at Imperial is affiliated with the National Institute of Health Research (NIHR) Imperial Patient Safety Translational Research Centre. The NIHR Imperial Patient Safety Translational Centre is a partnership between the Imperial College Healthcare NHS Trust and Imperial College London. The Department of Primary Care \& Public Health at Imperial College London is grateful for support from the NW London NIHR Applied Research Collaboration and the Imperial NIHR Biomedical Research Centre. The views expressed in this publication are those of the authors and not necessarily those of the NIHR or the Department of Health and Social Care. MRC has received consultancy advice, research funds, and speaker's honoraria from Medtronic, Abbott and Boston Scientific.

Patient consent for publication Not required.

Ethics approval We have approval from the Secretary of State and the Health Research Authority under Regulation 5 of the Health Service (Control of Patient Information) Regulations 2002 to hold confidential data and analyse them for research purposes (CAG ref 15/CAG/0005). We have approval to use them for research and measuring quality of delivery of healthcare, from the London-South East Ethics Committee (REC ref 20/L0/0611).

Provenance and peer review Not commissioned; externally peer reviewed.

Data availability statement Data may be obtained from a third party and are not publicly available. Deidentified Hospital Episode Statistics data as used in this study are available from NHS Digital for authorised users. 
Open access This is an open access article distributed in accordance with the Creative Commons Attribution 4.0 Unported (CC BY 4.0) license, which permits others to copy, redistribute, remix, transform and build upon this work for any purpose, provided the original work is properly cited, a link to the licence is given, and indication of whether changes were made. See: https://creativecommons.org/ licenses/by/4.0/.

\section{ORCID iDs}

Alex Bottle http://orcid.org/0000-0001-9978-2011

Paul P Aylin http://orcid.org/0000-0003-4589-1743

Martin R Cowie http://orcid.org/0000-0001-7457-2552

\section{REFERENCES}

1 Savarese G, Lund LH. Global public health burden of heart failure. Card Fail Rev 2017;3:7-11.

2 Lloyd-Jones D, Adams RJ, Brown TM, et al. Executive summary: heart disease and stroke statistics--2010 update: a report from the American Heart Association. Circulation 2010;121:948-54.

3 Conrad N, Judge A, Tran J, et al. Temporal trends and patterns in heart failure incidence: a population-based study of 4 million individuals. Lancet 2018;391:572-80.

4 Lesyuk W, Kriza C, Kolominsky-Rabas P. Cost-Of-Illness studies in heart failure: a systematic review 2004-2016. BMC Cardiovasc Disord 2018;18:1-11.

5 Prinzing A, Herold U, Berkefeld A, et al. Left ventricular assist devices-current state and perspectives. J Thorac Dis 2016;8:E660-6.

6 Maciver J, Ross HJ. Quality of life and left ventricular assist device support. Circulation 2012;126:866-74.

7 Fang JC. Rise of the machines--left ventricular assist devices as permanent therapy for advanced heart failure. $N$ Engl $J$ Med 2009;361:2282-5.

8 Moazami N, Hoercher KJ, Fukamachi K, et al. Mechanical circulatory support for heart failure: past, present and a look at the future. Expert Rev Med Devices 2013;10:55-71.

9 Mcllvennan CK, Magid KH, Ambardekar AV, et al. Clinical outcomes after continuous-flow left ventricular assist device: a systematic review. Circ Heart Fail 2014;7:1003-13.

10 Rose EA, Gelijns AC, Moskowitz AJ, et al. Long-Term use of a left ventricular assist device for end-stage heart failure. $N$ Engl J Med 2001;345:1435-43.

11 Slaughter MS, Rogers JG, Milano CA, et al. Advanced heart failure treated with continuous-flow left ventricular assist device. $N$ Engl $J$ Med 2009;361:2241-51.

12 Theochari CA, Michalopoulos G, Oikonomou EK, et al. Heart transplantation versus left ventricular assist devices as destination therapy or bridge to transplantation for 1-year mortality: a systematic review and meta-analysis. Ann Cardiothorac Surg 2018;7:3-11.

13 Neyt M, Van den Bruel A, Smit Y, et al. The cost-utility of left ventricular assist devices for end-stage heart failure patients ineligible for cardiac transplantation: a systematic review and critical appraisal of economic evaluations. Ann Cardiothorac Surg 2014;3:439-49.
14 Hannan EL. Randomized clinical trials and observational studies. JACC Cardiovasc Interv 2008;1:211-7.

15 Sutcliffe P, Connock M, Pulikottil-Jacob R, et al. Clinical effectiveness and cost-effectiveness of second- and third-generation left ventricular assist devices as either bridge to transplant or alternative to transplant for adults eligible for heart transplantation: systematic review and cost-effectiveness model. Health Technol Assess 2013;17:1-499.

16 Bell H, Wailoo AJ, Hernandez M. The use of real world data for the estimation of treatment effects in NICE decision making, 2016. Available: www.nicedsu.org.uk

17 Bottle A, Aylin P, Bell D. Effect of the readmission primary diagnosis and time interval in heart failure patients: analysis of English administrative data. Eur J Heart Fail 2014;16:846-53.

18 Mehra MR, Uriel N, Naka Y, et al. A Fully Magnetically Levitated Left Ventricular Assist Device - Final Report. N Engl J Med 2019;380:1618-27.

19 Tsiouris A, Paone G, Nemeh HW, et al. Short and long term outcomes of 200 patients supported by continuous-flow left ventricular assist devices. World J Cardiol 2015;7:792-800.

20 Lietz K, Long JW, Kfoury AG, et al. Outcomes of left ventricular assist device implantation as destination therapy in the postREMATCH era: implications for patient selection. Circulation 2007;116:497-505.

21 John R, Naka Y, Smedira NG, et al. Continuous flow left ventricular assist device outcomes in commercial use compared with the prior clinical trial. Ann Thorac Surg 2011;92:1406-13.

22 Zimpfer D, Gustafsson F, Potapov E, et al. Two-Year outcome after implantation of a full magnetically levitated left ventricular assist device: results from the elevate registry. Eur Heart $J$ 2020;41:3801-9.

23 McGee E, Danter M, Strueber M, et al. Evaluation of a lateral thoracotomy implant approach for a centrifugal-flow left ventricular assist device: the lateral clinical trial. J Heart Lung Transplant 2019;38:344-51.

24 Kilic A, Acker MA, Atluri P. Dealing with surgical left ventricular assist device complications. J Thorac Dis 2015;7:2158-64.

25 Schaffer JM, Allen JG, Weiss ES, et al. Infectious complications after pulsatile-flow and continuous-flow left ventricular assist device implantation. J Heart Lung Transplant 2011;30:164-74.

26 British Heart Foundation. Heart matters. focus on: left ventricular assist devices. Available: https://www.bhf.org.uk/informationsupport/ heart-matters-magazine/medical/Ivads [Accessed 22 Oct 2020].

27 NHS Blood and Transplant. Annual report on mechanical circulatory support related to heart transplantation report for 2016/2017 (1 April 2007 - 31 March 2017). Available: https://nhsbtdbe.blob.core. windows.net/umbraco-assets-corp/6543/nhsbt-annual-report-onmcs-201617.pdf [Accessed 22 Oct 2020].

28 Burns EM, Rigby E, Mamidanna R, et al. Systematic review of discharge coding accuracy. J Public Health 2012;34:138-48.

29 Kirklin JK, Naftel DC, Pagani FD, et al. Seventh INTERMACS annual report: 15,000 patients and counting. J Heart Lung Transplant 2015;34:1495-504

30 Kirklin JK, Cantor R, Mohacsi P, et al. First annual IMACS report: a global International Society for heart and lung transplantation Registry for mechanical circulatory support. J Heart Lung Transplant 2016;35:407-12. 